\title{
Utilization of healthcare services among children members of Medical Insurance for a New Generation
}

\author{
Ricardo Pérez-Cuevas, DrSc, ${ }^{(1,2)}$ Svetlana V Doubova, MSc, ${ }^{(2)}$ \\ Sergio Flores-Hernández, MSc, ${ }^{(3)}$ Onofre Muñoz-Hernández, MSc. ${ }^{(4)}$
}

\begin{abstract}
Pérez-Cuevas R, Doubova SV, Flores-Hernández S, Muñoz-Hernández $\mathrm{O}$. Utilization of healthcare services among children members of Medical Insurance for a New Generation. Salud Publica Mex 20I2;54 suppl I:S28-S4I.
\end{abstract}

\begin{abstract}
Objective. To describe the utilization and associated factors for preventive and curative care utilization among children affiliated to the Medical Insurance for a New Generation (SMNG). Materials and Methods. Data from the 2009 National Survey of SMNG was analyzed. Results. The analysis represented I 316867 children; $25 \%$ of urban and $37.5 \%$ of rural mothers that took their children to well-child visits. Covariates associated with preventive care utilization were children $<12$ months, low-birth weight, history of infectious or other diseases, mother $>35$ years, mother's literacy level of bachelor degree, housewife, attendance at $>7$ antenatal care visits, and living in a rural area. Curative care: $12 \%$ attended emergency room services, $5.4 \%$ were hospitalized and $66 \%$ received ambulatory care. Covariates associated with curative care utilization: child history of frequent diseases, mother living with husband/partner, mother's literacy level of bachelor degree, attendance $>7$ antenatal care visits and having paid work. Conclusion. It is needed to reinforce the programs encouraging mothers to seek preventive care regularly.
\end{abstract}

Key words: access; use; health services; primary care; Mexico
Pérez-Cuevas R, Doubova SV, Flores-Hernández S, Muñoz-Hernández $\mathrm{O}$. Utilización de servicios de atención a la salud en niños afiliados al Seguro Médico para una Nueva Generación. Salud Publica Mex 2012;54 supl I:S28-S4I.

\section{Resumen}

Objetivo. Describir el uso y factores asociados para la atención preventiva y curativa de niños afiliados al Seguro Médico para una Nueva Generación (SMNG). Material y métodos. Análisis de la información de la Encuesta Nacional SMNG 2009. Resultados. El análisis representó I 316867 niños; $25 \%$ de madres urbanas y $37,5 \%$ de rurales que llevaron a sus hijos para atención preventiva. Variables asociadas con atención preventiva regular: niños $<12$ meses, bajo peso al nacer, antecedentes de enfermedades infecciosas, madre $>35$ años, escolaridad licenciatura, ama de casa, asistencia a $>7$ visitas de atención prenatal y vivienda en zona rural. $12 \%$ acudió a servicios de urgencias, 5,4\% fueron hospitalizados y $66 \%$ recibió atención ambulatoria. Antecedentes de enfermedades infecciosas, madre que vive con su esposo o pareja, escolaridad licenciatura, asistencia a $>7$ visitas prenatales y tener un trabajo remunerado se asociaron con la utilización de servicios curativos. Conclusión. Es indispensable fomentar que las madres lleven a sus hijos regularmente a atención preventiva.

Palabras clave: acceso; utilización; servicios de salud; atención primaria; México

(I) Centro de Estudios Económicos y Sociales en Salud, Hospital Infantil de México Federico Gómez. México.

(2) Unidad de Investigación Epidemiológica y Servicios de Salud Siglo XXI, Instituto Mexicano del Seguro Social. México.

(3) Coordinación de Investigación en Salud, Instituto Mexicano del Seguro Social. México.

(4) Dirección de Investigación, Hospital Infantil de México Federico Gómez. México.

Received on: February 10, 20II - Accepted on: September 8, 201I

Corresponding author: MD. Sergio Flores-Hernández. Centro Médico Nacional Siglo XXI. Coordinación de Investigación, Edificio de las Academias. Av. Cuauhtémoc 330 Col. Doctores. 06726, México DF, México.

E-mail: sfloresh2@prodigy.net.mx 
$\mathrm{H}^{\mathrm{e}}$ ealth services utilization (HSU) is defined as "the extent to which a given population group uses a particular service or several services in a specified period". ${ }^{1}$ The degree of HSU depends on the type of service, i.e., ambulatory, hospital and emergency care; and the purpose of the service, i.e., preventive, curative or discretional, such as dental care. HSU differs widely within and among countries. Different theoretical approaches explain the variation of HSU, such as sociocultural, socio-demographic, social-psychological and organizational contexts, among others. Nevertheless, due to the lack of a systematic perspective to address each individual approach, it has been proposed to combine them. It has also been recommended that consideration is given to HSU determinants at individual, health services system and societal levels. ${ }^{2}$

At the individual level, such determinants are:

1. Predisposing

a) Socio-demographic characteristics, including age, sex, marital status, education, race, occupation, family size, ethnicity, religion, etc.

b) Beliefs and values concerning health and illness, attitudes toward health services and knowledge about the disease.

2. Enabling

a) Family income, health insurance, type of regular source, access to healthcare;

b) Community such as ratios of health personnel and facilities to population, price of health services, region of the country (i.e., urbanrural).

3. Illness

a) Perceived: disability, symptoms, diagnoses, general state;

b) Evaluated: symptoms, diagnosis.

At the health services system level such determinants include:

1. Resources: volume and geographical distribution;

2. Organizational: access and structure.

At the societal level such determinants include:

1. Technology and norms are factors that also influence HSU.

In Mexico, as in other emerging economies, HSU is crucial for children younger than 2 years of age. Children should be high users of preventive healthcare, which has immediate and long-term positive effects on their health. Preventive care aims to: detect a disease in a timely manner, avoid or delay its occurrence and its complications when the condition is already present, avoid premature deaths, and improve the efficiency of health services. ${ }^{3}$ Most preventive care for young children is provided during the well-child visits that offer numerous opportunities for developmental assessment, anthropometric measurement, screening tests, vaccine administration and parental health education. ${ }^{4}$ There are several factors associated with the use of preventive care: child age, birth order, sickness, parent's literacy, family structure, mother's attitude toward the preventive services and geographical proximity of the household to the healthcare facility. ${ }^{5-9}$

Children are high users of the curative care service, mostly for acute illnesses that include diarrhea and acute respiratory infections. The perception of illness severity by the caretaker has been strongly associated with healthcare seeking; other associated factors are the child's age, household size, maternal literacy, religion, health insurance coverage, family income and geographical location. ${ }^{10-14}$

To our knowledge, the information focused on children's healthcare utilization in Mexico comes from national surveys. The National Survey of Health (ENSA 2000) ${ }^{15}$ and National Health and Nutrition Survey 2006 (ENSANUT 2006) ${ }^{16}$ reported that the age-adjusted immunization rates of children aged 1 to 2 years were $78.4 \%$ and $84.7 \%$ respectively, and the 2-week prevalence of acute respiratory infection was $13 \%$ and acute diarrhea 15\%. The National Coverage Surveys carried out with members of the Mexican Institute for Social Security (Instituto Mexicano del Seguro Social, IMSS) in 2004 , reported that $>84 \%$ of children $<2$ years old had one or more well-child visits, $68 \%$ had their complete immunization scheme according to the child's age; and $79 \%$ who suffered from diarrhea and $72 \%$ with respiratory infection received medical care. ${ }^{17}$

These surveys have also stressed the existence of asymmetries in the health status of Mexican children, such as high rates of neonatal deaths, persistence of anemia and malnutrition, and gaps in access to healthcare among different segments of the population. ${ }^{15,16,18-20}$ These problems have driven numerous policies and prompted the creation of different programs and interventions.

Several public programs address the different facets of social and healthcare needs of Mexican children. The program Arranque Parejo en la Vida focuses on providing information and high quality health services to pregnant women and their newborns in the counties or "municipios" of lower human development. Pregnant women receive antenatal, delivery and postpartum healthcare and care during obstetric emergencies. 
Newborns receive healthcare during the first 28 days of life with the aim of preventing disability and promoting healthy growth and development. ${ }^{21}$ Evaluations have reported an improvement in the co-ordination and community participation of the care for pregnant women, but the component for the newborn was not fully developed. ${ }^{22}$

Oportunidades is an anti-poverty program that focuses on poor families in rural and urban settings. It is a conditional cash transfer program that promotes regular school attendance, healthcare use, mainly preventive care, and the nutrition of children. It is expected that in the long run the program will improve societal conditions and decrease poverty. There are 4.5 million families affiliated to the Oportunidades program. Evaluations show that: "Oportunidades members have increased their school enrollment, have more balanced diets and are receiving more medical attention". A number of evaluations have been conducted, among which it is possible to identify Oportunidades as promoting better growth in children living in poor urban households. ${ }^{23,24}$

One of these programs is Medical Insurance for a New Generation (Seguro Médico para una Nueva Generación, SMNG), which is a medical insurance for children born after December 2006 who have no social security. SMNG is an important component of Seguro Popular, which is a medical insurance for people without social security. It provides financial resources for healthcare for children through a capitated payment system, these being allocated to the Ministry of Health $(\mathrm{MoH})$ in each Mexican state. Provision of healthcare comprises ambulatory (preventive and curative care), and hospital services (emergency and in-patient care) at $\mathrm{MoH}$ facilities through a package of 116 medical care interventions. SMNG has several objectives that include promotion of preventive care and comprehensive coverage of healthcare. The long-term goal of SMNG is to reduce the incidence of diseases, disability and mortality of children until they reach the age of 5 years old.

The first nationwide evaluation of this program was conducted in 2009. One of the objectives of the evaluation was to learn about the demand perspective of healthcare for children affiliated to SMNG. This was interpreted as the utilization of preventive and curative care services. The 2009 SMNG survey followed a multistage design of sampling, stratification (rural/urban) and clustering (municipality). The sampling frame for this survey was taken from the registries of child members of the SMNG. In the first stage of sampling, municipalities were independently selected from each locality (strata). In the second stage, households were selected within each chosen municipality. Within each household, every mother of an SMNG-affiliated child undertook the survey. The weightings were adjusted to reduce non-response bias at the interview stage. ${ }^{25} \mathrm{~A}$ detailed description of the survey design and its major components are described elsewhere.

This paper has two objectives:

1. To describe preventive and curative care utilization among children 2 years of age and younger affiliated to SMNG.

2. To analyze the associated factors for the utilization of regular preventive care and curative care.

\section{Materials and methods}

A nation-wide survey with national level and urbanrural representativeness was conducted by Hospital Infantil de México Federico Gómez (HIMFG) and the National Institute of Statistics (Instituto Nacional de Estadística y Geografía (INEGI). The units of analysis were children affiliated to SMNG who were born between December 1st, 2006 and September 30th, 2008. The study followed a probabilistic design. SMNG registries were the basis for the sampling frame; a 3-stage cluster sampling approach was followed. The primary sampling units were counties, the secondary sampling units were the towns or communities, and the tertiary sampling unit was the SMNG member. A subsample of children for anthropometric measurements (nutritional status and hemoglobin) was taken. The sample size was estimated using a standard demographic formula for surveys that resulted in 12240 children. The subsample for anthropometric measurements resulted in 6240 children and the subsample for hemoglobin measurements 760 children. The sample is representative of 1.5 million children affiliated to SMNG. A more detailed description of the survey's method is described elsewhere.

The survey was conducted from March 16 to April 10, 2009. Data was collected by interviewing the mother or primary caretaker; an electronic questionnaire was used to gather the information.

To evaluate preventive care the survey collected data about the following variables:

a) Attendance at the well-child program visits; b) visual and hearing screening tests; c) iron and vitamin A supplementation and prescription of anti-parasitic drugs; d) attendance of the mother at educational activities to promote health; and e) immunizations, whether the child had his/ her immunization card and if he/ she had been vaccinated against measles/mumps/rubella vaccine (MMR), pentavalent combination, diphtheria, tetanus, acellular pertussis, polio and Haemophilus influenzae 
type b vaccines (DTaP-IPV/ Hib), pneumococcal, seasonal influenza and rotavirus vaccines.

For the purposes of this analysis, regular utilization of preventive care was defined as the attendance of the child to the well-child visits program in accordance with the $\mathrm{MoH}$ recommendations. These state that the child should attend a well-child visit once after birth, then at least every two months during the first year of life. Thereafter the child should attend at least every six months during the second year of life. Preventive care utilization definitions classified the children as regular users and irregular or non-users. Regular users were children who followed the $\mathrm{MoH}$ recommendations and the irregular or non-users were those who did not attend the recommended visits. The age of the child was taken into account to evaluate regularity of attendance. Completeness of the immunization scheme for each vaccine was considered as such if the child was fully immunized according to his/her age with respect to the recommended number of doses.

To analyze curative care, the survey included the following variables: information about ambulatory visits, emergency room and hospital admissions for the last episode of diarrhea, acute respiratory infections and other causes. Asking about the last episode allowed avoiding the recall bias. For such conditions, the questions explored whether the child had received curative care, the type of facility where the care was provided, the treatment prescribed, and the reasons for the non-utilization of health services. Curative care was classified in two categories: users (one or more visits) and non-users (the mother declared that she had not taken the child to be seen by a health provider for any of the above-mentioned conditions).

In addition, the survey explored the awareness of the mother about her child's SMNG affiliation status. For those children whose mother reported being aware of her child's affiliation with SMNG and utilized healthcare services, we explored several access variables: a) the time required to travel from home to the health facility; b) travel expenses; c) waiting times to receive care; and, d) satisfaction with the medical doctor in the regular source of healthcare.

\section{Socio-demographic and family characteristics variables:}

a) Child's characteristics: age, sex, history of low birth weight, acute diarrhea, acute respiratory infections and other diseases that happened during his/her lifetime. "Other diseases" were 1) acute diseases - other than acute diarrhea and acute respiratory infections - such as measles, rubella, parasitic diseases, injury, poisoning and other consequences of acute external causes; and 2) chronic conditions, including diseases of the blood and blood-forming organs, neoplasms, endocrine, nutrition and metabolic diseases, mental and behavioral disorders.

b) Mother's characteristics: age ( $<20$ years; $20-34$ years and $\geq 35$ years); literacy level (less than a bachelor's degree or a bachelors degree or higher); living with husband / partner; formal employment (paid work or housewife); history of antenatal care utilization during last pregnancy, and knowledge about warnings signs of acute diarrhea and acute respiratory infection. The knowledge about warning signs was classified when the mother mentioned at least two signs (for each disease) that prompted her to seek medical care.

c) Socio-demographic characteristics: place of residence (urban-rural), index of socio-economic level which was constructed according to the Bronfman's inde ${ }^{26}$ that takes into account the material of the floor of the house, availability of drinkable water, form of elimination of excretes, index of the level of staking and schooling of the head of the family.

\section{Statistical analysis}

The 2009 National Survey of SMNG used probabilitybased complex sample designs to produce estimates of health conditions, socio-demographic characteristics and healthcare utilization. Of all registered variables, we obtained descriptive statistics such as proportions, means and their standard errors. To make population inferences from a sample of data statistically valid, standard errors were computed using procedures that took into account the complex nature of the sample design.

Given that the primary sampling units (children) were sampled with unequal probability, the inverseprobability weighting was calculated. This allowed giving the primary sampling units unequal weights in the analysis because they were sampled with unequal probability in each county and state. The probability of being selected was calculated considering the counties and communities selected with a proportional probability to the member in each state and county, respectively. To facilitate the interpretation of the results, the tables show the actual number of sampled subjects although the prevalence was estimated by using the weighted values.

To evaluate the crude association between healthcare utilization (preventive or curative) and independent variables, we performed a bivariate analysis that allowed estimation of the crude odds ratios (OR) and 
95\% confidence intervals (95\% CI). We used clinically ${ }^{27}$ and statistically relevant variables to fit a logistic regression model for each type of healthcare utilization (preventive and curative), and obtained the survey-adjusted odds ratios and standard errors. The goodness-of-fit test for survey samples was used to assess the model calibration..$^{28}$

Due to the results of previous studies regarding the existing differences in the relationship between healthcare utilization and other covariates dependent on the place of residence (urban-rural), we evaluated whether the place of residence was an effect-modifier.

All analyses were performed with the statistical program Stata and a method to adjust for the effect of the sample design was applied, taking into account complex sampling techniques. ${ }^{29}$ The Taylor series linearization method was used for estimating the population characteristics. To analyze only a portion of the survey data (a sub-population), we used the "sub-pop" option to identify the observations that were to be included in the estimate. To compute the variance, the strata with a single sampling unit were centered at the overall mean.

\section{Results}

The analysis was conducted with 7854 families with children affiliated to SMNG; using the expansion factors, this is equivalent to 1316867 children 2 years or younger.
Figure 1 describes the flow chart of the sampling selection and the final number of children included in the analysis. The diagram describes the original estimated sample size before $(\mathrm{n}=8200)$ and, after the design effect ( $n=12$ 240), the number of eligible children but not recruited $(n=2790)$, the total number of recruited children $(n=9450)$, and the number of children included in the analysis ( $\mathrm{n}=7$ 854).

Table I presents the data on access and satisfaction with the medical doctor and causes of non-utilization of healthcare findings. About $49 \%$ of urban mothers and $44.6 \%$ of rural mothers were aware that their children had been affiliated to SMNG. Given that SMNG is a program of Seguro Popular, it is worth mentioning that $42.8 \%$ of mothers answered that they were aware of their membership to Seguro Popular. For the purposes of this study, we decided to analyze only those who were aware of the membership of SMNG, given that our focus was healthcare for their children. Among those who were aware of the affiliation status, $73 \%$ mentioned that they had used the services; within this group, most $(>81 \%)$ mentioned that it took 30 minutes or less to get to the health facility from home and the average transportation cost was $<$ US\$2.30 (MX\$30.00). Almost 70\% mentioned that their waiting time to receive care was $>1$ hour. Mothers living in rural areas were slightly more satisfied $(77.1 \%)$ with the medical doctor in the regular source of care than urban mothers (71.3\%). Approximately $27 \%$ of mothers (in both, rural and urban groups) answered that they

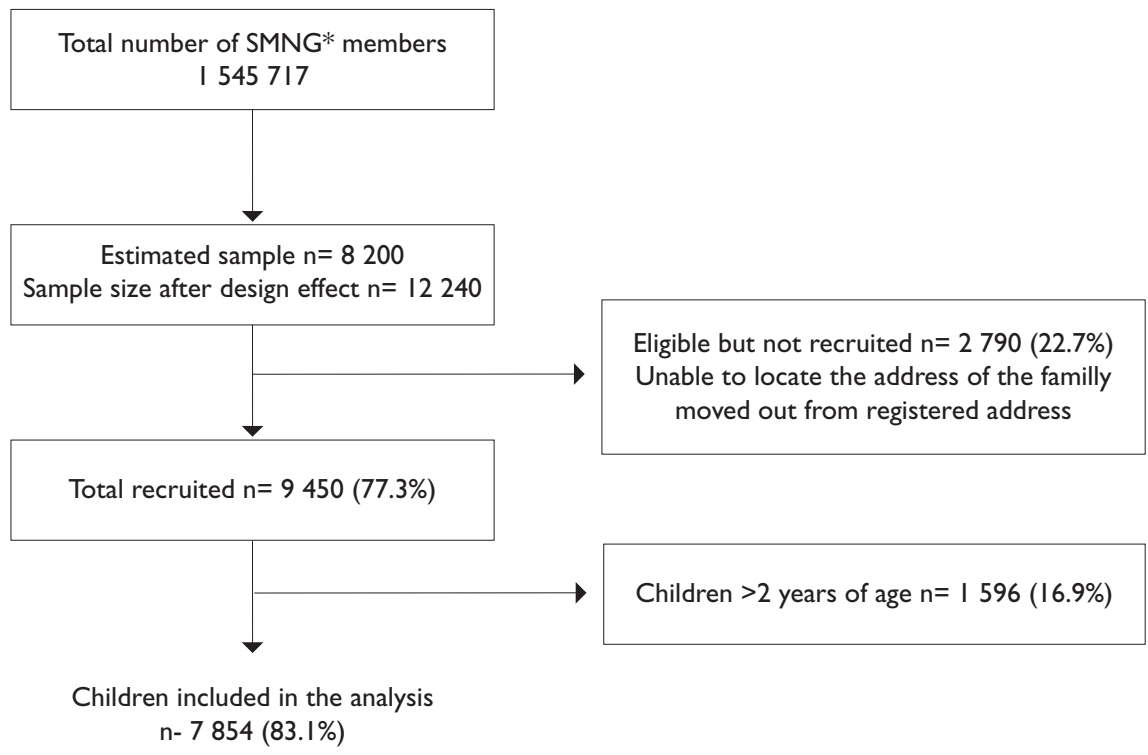

* SMNG: Medical Insurance for a New Generation

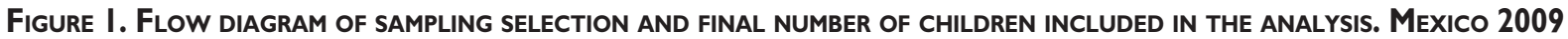


Table I

ACCESS AND SATISFACTION WITH MEDICAL DOCTOR AND CAUSES FOR NO UTILIZATION OF HEALTH SERVICES; NATIONAL Survey of Medical Insurance for a New Generation, Mexico 2009

\begin{tabular}{|c|c|c|c|c|}
\hline \multirow[b]{2}{*}{ Characteristics } & \multicolumn{2}{|c|}{ Urban } & \multicolumn{2}{|c|}{ Rural } \\
\hline & Sample & $\%$ & Sample & $\%$ \\
\hline
\end{tabular}

\begin{tabular}{|c|c|c|c|c|}
\hline Awareness about SMNG affiliation* & $n=3702$ & & $n=4 \mid 52$ & \\
\hline Yes & 1733 & 49.2 & 2267 & 44.6 \\
\hline No & 1969 & 50.8 & 1885 & 55.4 \\
\hline Utilization of health services among those aware of SMNG & $\mathrm{n}=1964$ & & $n=2264$ & \\
\hline Yes & 1415 & 73.1 & 1674 & 73.0 \\
\hline No or do not answer & 549 & 26.9 & 590 & 27.0 \\
\hline Time required to travel from home to health facility* & $n=1404$ & & $n=1664$ & \\
\hline$\leq 30$ minutes & 1185 & 83.8 & 1349 & 81.0 \\
\hline$>30$ minutes & 219 & 16.2 & 315 & 19.0 \\
\hline Travel expenses* & $n=|4| 4$ & & $n=1674$ & \\
\hline$\leq 30$ pesos & 1242 & 87.7 & 1430 & 85.1 \\
\hline$>30$ pesos & 172 & 12.3 & 244 & 14.9 \\
\hline Waiting time to receive care* & $n=1412$ & & $n=1672$ & \\
\hline$\leq 1$ hour & 432 & 30.2 & 502 & 29.9 \\
\hline$>$ I hour & 980 & 69.8 & I I70 & 70.1 \\
\hline Satisfaction with medical doctor in a regular source of SMNG health care* & $n=|4| 3$ & & $n=1674$ & \\
\hline Yes & 1003 & 71.3 & 1299 & 77.1 \\
\hline No & 410 & 28.7 & 375 & 22.9 \\
\hline Cause for no utilization of health services & $n=549$ & & $n=590$ & \\
\hline I do not need it* & 256 & 47.7 & 351 & 60.1 \\
\hline I prefer another health services* & 80 & 15.0 & 69 & $1 \mathrm{I} .4$ \\
\hline The waiting time is long* & 57 & 11.2 & 43 & 7.6 \\
\hline The facility is far from home* & 51 & 8.5 & 54 & 9.7 \\
\hline I do not know how it works* & 53 & 9.1 & 43 & 7.2 \\
\hline His/her health care was denied* & 46 & 8.5 & 32 & 5.5 \\
\hline There are too many formalities & 35 & 6.9 & 39 & 7.1 \\
\hline The quality of care is poor* & 32 & 6.4 & 32 & 4.9 \\
\hline I do not know where to take it* & 29 & 4.6 & 22 & 3.8 \\
\hline The schedule is inadequate* & 38 & 7.7 & 13 & 2.3 \\
\hline There is no medical doctor* & 12 & 2.3 & 14 & 3.0 \\
\hline The child has another medical insurance* & 17 & 3.2 & 4 & 0.5 \\
\hline The transportation is expensive* & 6 & 0.9 & 9 & 1.7 \\
\hline The health care services are expensive* & I & 0.1 & 4 & 0.6 \\
\hline$* p<0.0001$ & & & & \\
\hline
\end{tabular}

did not use the $\mathrm{MoH}$ services. The most frequent answer for not attending health services was that the mother considered that her child did not need healthcare (urban $47.7 \%$, rural $60.1 \%$ ), and the next answer was that they preferred to take the child to another healthcare service (urban 15.0\%, rural 11.4\%). Long waiting times were the cause of non-utilization by $11.2 \%$ of urban mothers.

Preventive care utilization is illustrated in Table II. The analysis was made using the information of the total sample of interviewed mothers. We observed that 25\% 
Table II

\section{Characteristics of preventive care utilization. National Survey of Medical Insurance for a New Generation, Mexico 2009}

Characteristics

Preventive care

Well-child visits utilization $\S$

Regular

Irregular or No utilization

Sample
$\mathrm{n}=34$
2589
$\mathrm{n}=2270$
$\mathrm{I}$
$\mathrm{I}$
8453

Urban $\%$

\begin{tabular}{cc}
\multicolumn{2}{c}{ Rural } \\
\hline Sample & $\%$
\end{tabular}

Institutions that provided preventive care* Ministry of Health ${ }^{\S}$

Social Security

Private services ${ }^{\S}$

Other institutions ${ }^{\S}$

Without information ${ }^{\S}$

$n=2270$

$\begin{array}{rrrr}3412 & n=3977 \\ 889 & 25.4 & 1511 & 37.5 \\ 2523 & 74.6 & 2453 & 62.5\end{array}$

Preventive and screening procedures

$=2270 \quad n=3 \quad 107$

Vision examination ${ }^{\S}$

$193 \quad 50.8$

Hearing examination $\S$

379

379

Iron supplementation ${ }^{\S}$

Vitamin A supplementation $\S$

Prescription of anti-parasitic drugs ${ }^{\S}$

669

938

78

45

4

50.8
4.0

$=3107$

$4.0 \quad 27$

58.5

6.9

2.0

38.9

95

0.8

I 146

3.0

3.0

Attendance of the mother to educational activities to promote health ${ }^{\S}$

375

17.1

$n=3107$

\begin{tabular}{lrl}
17.1 & 444 & 14.1 \\
\hline 23.9 & 557 & 18.2 \\
\hline 29.3 & 857 & 27.8 \\
\hline 40.6 & 1326 & 42.7 \\
\hline 15.4 & 738 & 24.0
\end{tabular}

$n=2560$

382

13.4

$n=3295$

I 146

35.1

Immunization ${ }^{\ddagger}$

Immunization card§

$n=3702$

2672

$\mathrm{n}=1757$

I 478

71.9

$\mathrm{n}=4 \mid 52$

Measles/Mumps/Rubella ${ }^{\S}$

Complete vaccination

$n=2672$

1906

Complavalent combination

Incomplete vaccination

Without vaccination

Missing data

725

13

13

83.3

3133

$\mathrm{n}=2 \quad 107$

$83.3 \quad 1797$

$n=3 \quad 132$

\begin{tabular}{rrr} 
& $\mathrm{n}=3132$ & \\
71.1 & 2345 & 74.7 \\
\hline 27.4 & 730 & 23.4 \\
\hline 0.6 & 13 & 0.4 \\
\hline 0.9 & 44 & 1.5
\end{tabular}

Pneumococcal vaccine ${ }^{\S}$

$n=2672$

\begin{tabular}{rrrr}
\hline 455 & 54.2 & $\mathrm{n}=3 \mid 32$ & 54.0 \\
\hline 359 & 14.6 & 377 & 11.9 \\
\hline 115 & 29.9 & 1005 & 32.1 \\
43 & 1.3 & 59 & 2.0
\end{tabular}

Without vaccination

Missing data

$n=2672$

\begin{tabular}{rrrr}
\hline 616 & 59.7 & 1915 & 60.4 \\
\hline 428 & 16.5 & 430 & 14.4 \\
\hline 624 & 23.6 & 769 & 24.5 \\
\hline 4 & 0.2 & 18 & 0.7
\end{tabular}

Seasonal influenza vaccine $e^{\S}$

$n=3022$

Complete vaccination

Incomplete vaccination

Without vaccination

Missing data

954
728
875

\begin{tabular}{rrr}
36.4 & I 143 & 37.3 \\
\hline 27.6 & 938 & 31.3 \\
\hline 34.8 & 878 & 29.1 \\
\hline 1.2 & 63 & 2.2
\end{tabular}

* The figure corresponds to those who answered that they received preventive care; 23 urban and 30 rural children reported that they received preventive care in more than one institution

₹ The figures correspond to the groups of age of children that should receive the vaccines

$\S p<0.0001$ 
of urban mothers and $37.5 \%$ of rural mothers took their child for the well-child visits as recommended (please see above mentioned definitions) and most of children were taken irregularly or not taken at all. Analysis of the institutions where the children received care shows that the $\mathrm{MoH}$ provided $>50 \%$ of these services, and up to $38 \%$ of mothers did not specify where the children were taken.

Between the expected preventive and screening procedures, the most frequent was vitamin A supplementation (urban $40.6 \%$, rural $42.7 \%$ ), and the least frequent was visual examination (urban $17.1 \%$, rural $14.1 \%)$. Iron supplementation, hearing examination and prescription of anti-parasitic drugs showed low percentages. Rural mothers attended to educational activities more often than urban mothers (35.1 and $13.4 \%$, respectively). Immunizations were checked in two ways: whether the mother had the child immunization card, and reviewing the vaccines registered in the card. Seventy-one percent of urban mothers and 74.9\% of rural mothers had the card.

Vaccines analysis was carried out by searching for individual vaccines. The percentages of completed schemes, adjusted to the age of the child, were as follows: Measles/Mumps/Rubella: urban 83.3\%, rural $85 \%$; pentavalent combination: urban $71 \%$, rural $74.7 \%$; rotavirus vaccine: urban $59.7 \%$, rural $60.4 \%$; seasonal influenza vaccine: urban $36.4 \%$, rural $37.3 \%$.

Table III depicts the multivariate logistic regression analysis of the associated factors for regular preventive care utilization. It shows that the main child covariates associated with regular preventive care were: children $<12$ months of age (OR 2.0; 95\% CI 1.77-2.26), born with low-birth weight (OR 1.53; 95\% CI1.21-1.93), and history of infectious or other diseases (OR 1.52; 95\% CI1.12-2.06). The mother covariates were: $>35$ years (OR 1.33; $95 \%$ CI 1.02-1.73), mother's literacy level of bachelor degree or higher (OR 1.32; 95\% CI 1.09-1.59), being housewife without formal employment (OR 1.24; 95\% CI 1.01-1.51), attendance of the mother at $>7$ antenatal care visits (OR $1.62 ; 95 \%$ CI1.38-1.89). Regarding the socio-demographic characteristics, living in a rural area was also associated with regular use of preventive care (OR 1.90; 95\% CI 1.63-2.22).

Characteristics of curative care utilization are shown in Table IV. This analysis was of children who suffered from acute diarrhea, acute respiratory infection or other acute and chronic conditions. Up to $83 \%$ of children used the services. Regarding the institutions that provided curative care, $80 \%$ of children in the rural area were taken to $\mathrm{MoH}$ facilities, whereas $61 \%$ of urban children used the services of this institution. Private services were used by $35 \%$ of urban and $22 \%$ of rural children.
According to the type of curative care, $66 \%$ received ambulatory care; $5 \%$ were hospitalized and $>12 \%$ (urban $15 \%$, rural $12 \%$ ) attended emergency room services. The main causes of ambulatory and hospital care were diarrhea and acute respiratory infections, although the percentages of children receiving care for a chronic condition were also high (urban 35.8\%, rural 31.0\%).

Table $\mathrm{V}$ shows the multivariate logistic regression analysis of the associated factors for curative care utilization. The history of diseases in the children other than acute diarrhea or respiratory infection prompted use of curative care (OR 7.75; 95\% CI 4.3-14.0). The mother's covariates associated with utilization of curative care were: living with husband / partner (OR1.22; 95\% CI1.011.47), mother's literacy level of bachelor degree or higher (OR 1.48; 95\% CI 1.14-1.92), attendance of the mother at $>7$ antenatal care visits (OR 1.26; 95\%CI 1.06-1.49), if the mother had paid work (OR 1.02; 95\% CI 1.02-1.69) adjusted to place of residence. The results previously described for preventive and curative care utilization were similar when we constructed the multiple logistic regression modeling stratifying the sample according to the place or residence (urban/rural). There was a significantly higher possibility of curative care utilization when a rural mother attended $>7$ antenatal care visits.

\section{Discussion}

The main results of this evaluation show that SMNG needs further strategies and effort to become a wellknown health insurance that allows mothers to use regularly preventive and curative care services for their children.

Access and use of both, preventive and curative care have not been fully explored in Mexican children and, from our perspective, both should be analyzed independently, given that the underlying factors that prompt users to seek any of these services are different. Preventive care aims to stop the disease appearing, while curative care aims to recover or improve the previous health status that the child had before getting sick.

The results of the comprehensive evaluation of key aspects of preventive care in this study, such as regularity of attendance at well-child visits and the percentage of children who underwent preventive and screening procedures, including coverage of selected vaccines, show that there is a wide margin for improvement.

The importance of preventive care is well known to healthcare providers; the public, however, does not really perceive preventive care as a health need that should prompt demand. The benefits of curative care are immediately observable, while for preventive care the symptoms of a disease have not presented, yet, or 
Table III

AsSOCIATION BETWEen REgULAR PREVENTIVE CARE UTILIZATION AND CHILD, MOTHERS AND SOCIO-DEMOGRAPHIC characteristics. National Survey of Medical Insurance for a New Generation, Mexico 2009

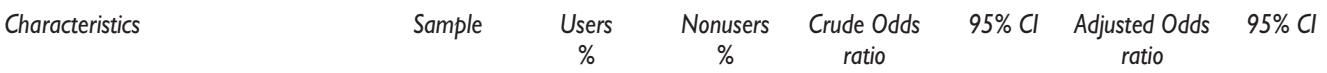

Child characteristics

\begin{tabular}{|c|c|c|c|c|c|c|c|}
\hline Sex & $n=7376$ & & & & & & \\
\hline Male & 3770 & 29.0 & 71.0 & 1.0 & & & \\
\hline Female & 3606 & 28.7 & 71.3 & 0.98 & $0.88-1.09$ & 1.0 & $0.90-1.10$ \\
\hline Age* & $n=7376$ & & & & & & \\
\hline$\leq 12$ months & 2417 & 37.5 & 62.5 & 1.85 & & & \\
\hline$>12$ months & 4959 & 24.5 & 75.5 & 1.0 & $1.65-2.08$ & 2.00 & $1.77-2.26$ \\
\hline Low birth weight* & $n=7 \quad \mid 43$ & & & & & & \\
\hline$<2500$ & 486 & 35.3 & 64.7 & 1.37 & & & \\
\hline$\geq 2500$ & 6657 & 28.4 & 71.5 & 1.0 & I.09-I.7I & 1.53 & $1.21-1.93$ \\
\hline History of acute infections or other diseases* & $n=7376$ & & & & & & \\
\hline No & 479 & 32.9 & 67.1 & 1.0 & & & \\
\hline Yes & 6897 & 37.8 & 62.2 & 1.40 & $1.03-1.89$ & 1.52 & I.12-2.06 \\
\hline
\end{tabular}

Mothers characteristics

Live with husband/partner $\quad n=7376$

\begin{tabular}{|c|c|c|c|c|c|c|c|}
\hline No & 1353 & 27.5 & 72.5 & 1.0 & & & \\
\hline Yes & 6023 & 29.2 & 70.8 & 1.09 & $0.93-1.27$ & 0.95 & $0.77-1.00$ \\
\hline Age* & $n=7314$ & & & & & & \\
\hline$<20$ years & 1093 & 27.7 & 72.3 & 1.0 & & & \\
\hline $20-34$ years & 5364 & 28.5 & 71.5 & 0.94 & $0.82-1.09$ & 1.04 & $0.86-1.26$ \\
\hline$\geq 35$ years & 857 & 32.7 & 67.3 & 1.22 & I.01-1.49 & 1.33 & $1.02-1.73$ \\
\hline Literacy* & $n=7320$ & & & & & & \\
\hline Less than bachelor s degree & 6028 & 28.2 & 71.8 & 1.0 & & & \\
\hline Bachelor s degree or higher & 1292 & 31.4 & 68.6 & 1.16 & $0.98-1.37$ & 1.32 & $1.09-1.59$ \\
\hline Formal employment* & $n=7320$ & & & & & & \\
\hline Paid work & 1303 & 24.5 & 75.8 & 1.0 & & & \\
\hline Housewife & 6017 & 30.1 & 69.9 & 1.35 & $1.13-1.61$ & 1.24 & $1.01-1.51$ \\
\hline Antenatal care use during last pregnancy* & $n=7043$ & & & & & & \\
\hline$<7$ visits & 2837 & 23.4 & 76.6 & 1.0 & & & \\
\hline$\geq 7$ visits & 4206 & 32.5 & 67.5 & 1.58 & I.35-I.84 & 1.62 & $1.38-1.89$ \\
\hline Awareness about SMNG affiliation & $n=7376$ & & & & & & \\
\hline No & 3430 & 27.1 & 72.9 & 1.0 & & & \\
\hline Yes & 3946 & 30.5 & 69.5 & 1.18 & $1.01-1.38$ & 1.14 & $0.98-1.32$ \\
\hline
\end{tabular}

Socio-demographic characteristics

Place of residence

$n=7376$

\begin{tabular}{lrrrrrrr}
\hline Urban & 3412 & 25.4 & 74.6 & 1.0 & & \\
\hline Rural & 3964 & 37.5 & 62.5 & 1.76 & $1.51-2.05$ & 1.90 & $1.63-2.22$ \\
\hline Socio-economic index & $\mathrm{n}=7376$ & & & & & \\
\hline Bad & 1829 & 28.2 & 71.8 & 1.0 & & & \\
\hline Regular & 3718 & 28.3 & 71.7 & 0.95 & $0.83-1.09$ & 0.98 & $0.80-1.19$ \\
\hline Good & 1829 & 30.4 & 69.6 & 1.10 & $0.94-1.30$ & 1.10 & $0.91-1.44$
\end{tabular}

Adjustments were made on all the variables in this table $* p<0.0001$ 
Table IV

\section{Characteristics of curative care utilization. National Survey of Medical Insurance for a New Generation, Mexico 2009}

\begin{tabular}{|c|c|c|c|c|}
\hline Characteristics & & & & \\
\hline Utilized curative services & $n=3430$ & $\%$ & $n=3886$ & $\%$ \\
\hline Yes & 2876 & 83.4 & 3188 & 81.0 \\
\hline No & 554 & 16.6 & 698 & 19.0 \\
\hline Institutions that provided curative care* & $n=2876$ & & $n=3 \quad 188$ & \\
\hline Ministry of Health ${ }^{\ddagger}$ & 1822 & 61.5 & 2557 & 80.0 \\
\hline Social Security $\ddagger$ & 92 & 3.4 & 43 & 1.4 \\
\hline Private services $\ddagger$ & 996 & 35.7 & 711 & 22.5 \\
\hline Other institutions ${ }^{\ddagger}$ & 242 & 9.0 & 140 & 4.5 \\
\hline
\end{tabular}

\begin{tabular}{lrrrr} 
Type of curative care & & & \\
\hline Ambulatory care & \\
\hline Hospitalization & 2260 & 66.1 & 2627 & 66.7 \\
\hline Emergency department visits $^{\ddagger}$ & 190 & 5.4 & 213 & 5.4 \\
\hline
\end{tabular}

\begin{tabular}{|c|c|c|c|c|}
\hline Ambulatory care & $n=2260$ & & $=2627$ & \\
\hline Due to diarrhea or respiratory infection ${ }^{\ddagger}$ & 2004 & 88.2 & 2420 & 91.8 \\
\hline Due to the other acute disease or injuries $\neq$ & 97 & 4.2 & 73 & 2.9 \\
\hline Due to chronic conditions ${ }^{\ddagger}$ & 159 & 7.6 & 134 & 5.3 \\
\hline
\end{tabular}

\begin{tabular}{lrrrr} 
Hospitalization & $\mathrm{n}=190$ & \multicolumn{3}{c}{$\mathrm{n}=213$} \\
\hline Due to acute diarrhea or respiratory infection $^{\ddagger}$ & 105 & 54.8 & 135 & 63.5 \\
\hline Due to other acute disease or injuries $^{\ddagger}$ & 18 & 9.4 & 12 & 5.4 \\
\hline Due to chronic condition $^{\ddagger}$ & 67 & 35.8 & 66 & 31.0
\end{tabular}

* The figure corresponds to those who responded that they received curative care; 276 urban and 263 rural children reported that they received curative care in more than one institution

$\ddagger p<0.0001$

may be unnoticed, so people do not see any immediate benefit. $^{3}$

To demand health services, the individual should be aware that he/she is within the medical system, know the benefits that he or she is entitled to receive, and have access to the usual source of care. ${ }^{30}$ In our context, this means that the mother should know that: her child is entitled to receive healthcare, insurance (SMNG) is covering most of the expenses, and she is able to use the usual source of care.

In the study, we observed that only half the mothers were aware that their children had SMNG health insurance and that, among those who were aware, the rate of utilization (either for preventive or curative care) was high $(73 \%)$. We can also assume that they were aware of the regularity of the source of care, given that they knew where the facility was, the travel time required and the transportation cost to get to the facility.

Attending to preventive care regularly contributes to better monitoring of the child's growth and develop- ment. As mentioned earlier, attending regular well-child visits offers healthcare providers and parents numerous opportunities to administer the recommended preventive care, identify problems and implement timely measures. ${ }^{4}$ In the Mexican healthcare system there are three main sources of preventive care services: a) the well-child visits that are usually provided by a medical doctor, and by a maternal-child health nurse in social security institutions; b) preventive care in dedicated wards, where the child is taken to receive vaccines, be screened or receive supplements such as iron or vitamin A. In these settings nurses provide the services and the mother can take the child freely; although the child should be appointed to maintain the continuity of services, such as the schedule of vaccines; $c$ ) the National Weeks of Health, nation-wide campaigns that provide preventive care services (vaccines, supplements and anti-parasitic drugs). The system offers numerous opportunities to provide preventive care. Unfortunately, we found low rates of screening for common problems 
Table V

AsSOCIATION BETWEEN CURATIVE CARE UTILIZATION AND CHILD, MOTHERS AND SOCIO-DEMOGRAPHIC CHARACTERISTICS. National Survey of Medical Insurance for a New Generation, Mexico 2009

\begin{tabular}{|c|c|c|c|c|c|c|}
\hline Characteristi & Total Sample & $\begin{array}{c}\text { Users } \\
\%\end{array}$ & $\begin{array}{c}\text { Nonusers } \\
\%\end{array}$ & $\begin{array}{l}\text { Crude Odds } \\
\text { ratio }\end{array}$ & $95 \% \mathrm{Cl}$ & $\begin{array}{c}\text { Adjusted Odds } \\
\text { ratio }\end{array}$ \\
\hline
\end{tabular}

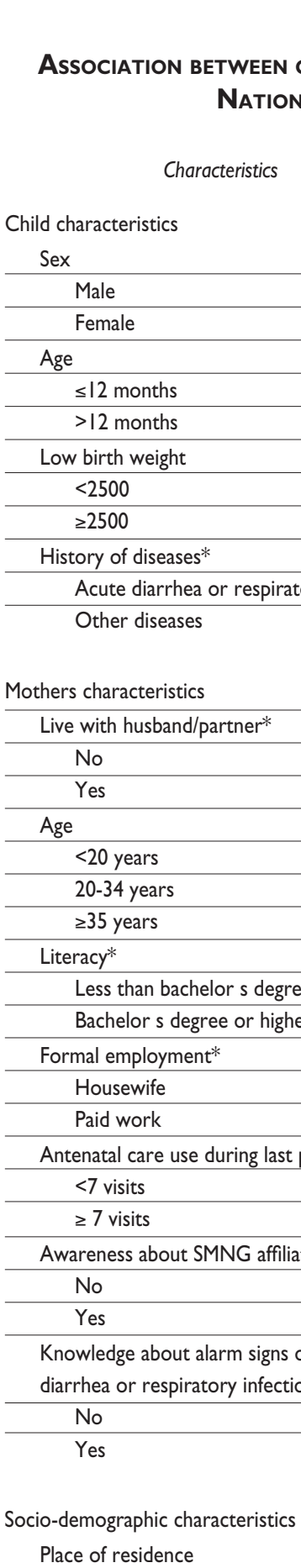

\begin{tabular}{|c|c|c|c|c|c|c|c|}
\hline Sex & $n=7316$ & & & & & & \\
\hline Male & 3768 & 82.9 & 17.1 & 1.0 & & & \\
\hline Female & 3548 & 82.5 & 17.5 & 0.97 & $0.84-1.12$ & 0.96 & $0.8 I-I .14$ \\
\hline Age & $n=7316$ & & & & & & \\
\hline$\leq 12$ months & 2365 & 82.2 & 17.8 & 0.95 & & & \\
\hline$>12$ months & 4951 & 82.9 & I7.| & 1.0 & $0.78-1.16$ & 0.95 & $0.75-1.19$ \\
\hline Low birth weight & $\mathrm{n}=708 \mathrm{I}$ & & & & & & \\
\hline$<2500$ & 474 & 86.5 & 13.5 & 1.33 & & & \\
\hline$\geq 2500$ & 66607 & 82.8 & 17.2 & 1.0 & $0.94-1.88$ & 1.38 & $0.95-2.02$ \\
\hline History of diseases* & $n=7316$ & & & & & & \\
\hline Acute diarrhea or respiratory infection & 6673 & 81.1 & 18.9 & 1.0 & & & \\
\hline Other diseases & 643 & 97.3 & 2.7 & 8.35 & $4.69-14.88$ & 7.76 & $4.3-14.0$ \\
\hline
\end{tabular}

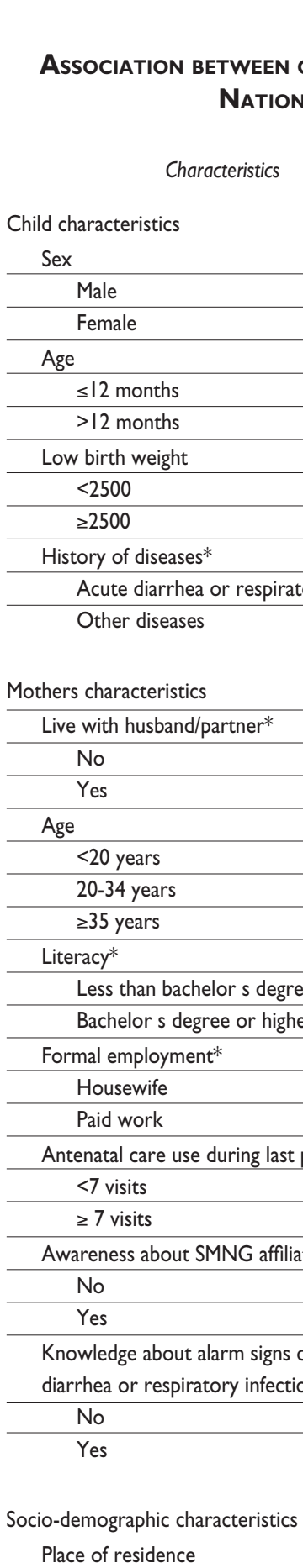

\begin{tabular}{|c|c|c|c|c|c|c|c|}
\hline Live with husband/partner* & $n=7316$ & & & & & & \\
\hline No & I 340 & 81.8 & 18.2 & 1.0 & & & \\
\hline Yes & 5976 & 82.9 & 17.1 & 1.08 & $0.90-I .31$ & 1.22 & $1.01-1.47$ \\
\hline Age & $\mathrm{n}=7255$ & & & & & & \\
\hline$<20$ years & 1090 & 83.9 & 16.1 & 1.0 & & & \\
\hline 20-34 years & 5334 & 82.2 & 17.8 & 0.87 & $0.72-1.05$ & 0.84 & $0.66-1.06$ \\
\hline$\geq 35$ years & 831 & 84.4 & 15.6 & 1.14 & $0.90-1.45$ & 0.99 & $0.72-1.34$ \\
\hline Literacy* & $n=7260$ & & & & & & \\
\hline Less than bachelor s degree & 5955 & 85.5 & 18.5 & 1.0 & & & \\
\hline Bachelor s degree or higher & 1305 & 87.4 & 12.6 & 1.58 & $1.25-1.99$ & 1.48 & $1.14-1.92$ \\
\hline Formal employment* & $n=7260$ & & & & & & \\
\hline Housewife & 5984 & 82.1 & 17.9 & 1.0 & & & \\
\hline Paid work & 1276 & 85.1 & 14.9 & 1.25 & $1.0-1.56$ & 1.30 & $1.02-1.68$ \\
\hline Antenatal care use during last pregnancy* & $\mathrm{n}=6897$ & & & & & & \\
\hline$<7$ visits & 2785 & 80.6 & 19.4 & 1.0 & & & \\
\hline$\geq 7$ visits & 4193 & 84.5 & 15.5 & 1.50 & $1.22-1.83$ & 1.26 & $1.06-1.49$ \\
\hline Awareness about SMNG affiliation & $n=7316$ & & & & & & \\
\hline No & 3382 & 82.8 & 17.2 & 1.0 & & & \\
\hline Yes & 3934 & 82.6 & 17.4 & 0.99 & $0.82-1.18$ & 0.92 & $0.75-1.13$ \\
\hline $\begin{array}{l}\text { Knowledge about alarm signs of acute } \\
\text { diarrhea or respiratory infection }\end{array}$ & $n=7316$ & & & & & & \\
\hline No & 4406 & 82.3 & 17.7 & 1.0 & & & \\
\hline Yes & 2910 & 83.3 & 16.7 & 1.07 & $0.91-1.27$ & 1.03 & $0.87-1.23$ \\
\hline
\end{tabular}

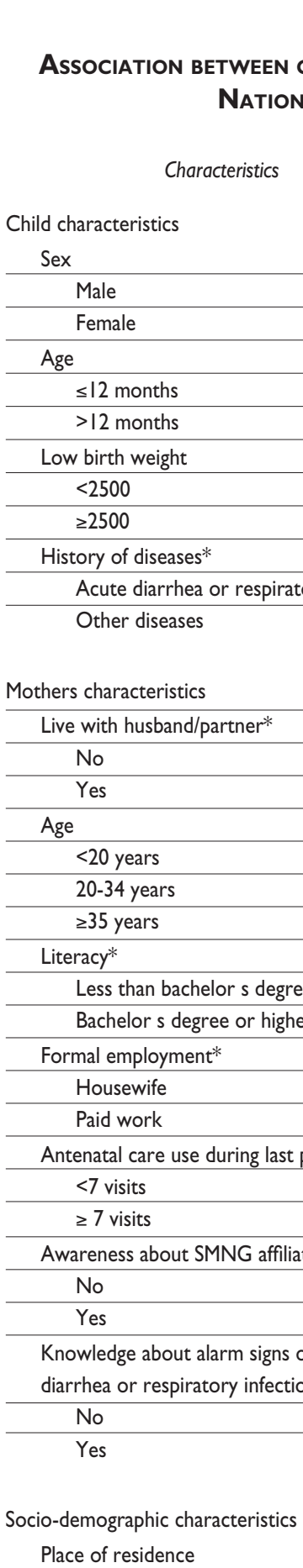

Place of residence

$n=7316$

\begin{tabular}{crrrrrrr}
\hline Urban & 3430 & 83.4 & 16.7 & 1.17 & & & \\
\hline Rural & 3886 & 81.0 & 18.9 & 1.0 & $1.0-1.38$ & 1.07 & $0.89-1.28$ \\
\hline Socio-economic index & $\mathrm{n}=7316$ & & & & & & \\
\hline Bad & 1817 & 82.2 & 17.8 & 1.0 & & & \\
\hline Regular & 3697 & 82.4 & 17.6 & 0.96 & $0.83-1.10$ & 0.98 & $0.81-1.19$ \\
\hline Good & 1802 & 83.7 & 16.3 & 1.10 & $0.92-1.33$ & 1.0 & $0.81-1.29$
\end{tabular}

Adjustments were made on all the variables in this table $* p<0.0001$ 
such as visual and hearing impairments and low rates of provision of iron and vitamin A supplements.

The coverage of the vaccines for children of this age group is not reaching the expected goals. The percentages of children with complete schemes according to their age had an important variation. Different surveys (ENSA $2000^{15}$ ENSANUT 2006 ${ }^{16}$ ) have shown that the progress in vaccine coverage has not been continuous. ENSANUT 2006 reported that $78.4 \%$ of children of oneyear-old and $84.7 \%$ of two-year-old children had completed the vaccination scheme. Comparing the results of ENSANUT 2006 and SMNG 2009, it is possible to observe that the percentages of children with individual vaccines are similar or even declining. MMR was $81.2 \%$ in ENSANUT 2006 and 85.0\% in SMNG 2009, whereas the pentavalent combination was $92.9 \%$ in ENSANUT 2006 and $74.7 \%$ in SMNG 2009. This finding points out the limitations of the vaccination program and the relevance of in-depth analysis of the potential associated factors that are negatively affecting the performance of a program that, until recently, was very successful.

There are important children- and mother-associated factors prompting the regular use of preventive care. We observe that children younger than one year of age, of low birth weight, and those who suffered from infectious diseases, were taken to preventive care more regularly. We interpret these factors as the perception of the mother about the vulnerability of her child, thus prompting her to seek preventive care.

Regarding the mother's characteristics, those who were $>35$ years, were housewives, with better schooling, and those who attended antenatal care visits and lived in rural areas were associated with regular attendance. It is possible that the mothers with more experience and literacy, and those who are housewives, were more aware of the importance of preventive care. The results of this analysis are similar to those reported in other studies..$^{5-9}$

It is necessary to encourage mothers to attend educational activities. We observed that a very low percentage of mothers (urban 13\% and rural 35\%) had attended educational activities to promote health. It is possible to consider that the 3-fold difference between urban and rural mothers could be attributed to the fact that the Oportunidades Program runs in rural areas, which makes it compulsory for its members to attend health and educational activities.

The findings of the preventive component of this study should be a wake-up call for healthcare providers to reinforce access and uptake of preventive care among SMNG affiliates. It is possible to assume that SMNG can become a key player in increasing utilization and provision of preventive care, thus contributing to the improvement of the health status of under-fives.
Patterns of services utilization for curative care show that infectious diseases such as diarrhea and acute respiratory infections are still the main causes of ambulatory and hospital care services. We also observed that a significant percentage of children seek care due to other diseases. The importance of in-depth evaluation of how often children receive healthcare due to infectious diseases relies upon several well-known facts. The mother should know how to provide early care at home and be able to identify warning signs that would indicate that medical attention is required. At this point, having access to medical care will avoid potential complications and SMNG mitigates the lack of access.

Analysis of the associated socio-demographic factors to utilize curative care services showed that the covariates mothers living with their partners, with high literacy levels and attendance to antenatal care and having paid work were significant. This result shows that mothers who are used to attending healthcare are the ones that will take their children for medical treatment. This finding is consistent with other studies in which some factors such as the mother's literacy and family income among others are related to healthcare use. ${ }^{10-14} \mathrm{In}$ our analysis, the covariates mother living with a partner and having paid work, can be interpreted as the possibility of regular income. Also, we observed that if the child suffered from a disease other than diarrhea and acute respiratory infection, this had a strong influence on the use of curative care. This could be interpreted positively in terms that the family, particularly the mother, takes care of the child when he or she gets sick with diarrhea or acute respiratory infections more often than in the past, and health-seeking behavior is shifting to other conditions that deserve medical care. Also, it seems that if the mother has established a pattern as a frequent user of healthcare (our proxy is antenatal care), she will replicate the pattern for her child.

This study has several strengths and limitations worth mentioning. Among the strengths is the sample design, which aimed to have national representativeness and urban-rural representativeness. The rate of acceptance to answer the interview was $>98 \%$. The study has limitations such as the lack of a comparison group that would allow making inferences about the gains attributable to the program. Logistical and economic reasons accounted for this decision. This was the first nation-wide survey and it was based upon the registries of SMNG; this required us to use the list for the random selection of the SMNG members' households to visit. Having a similar list of non-SMNG members was not feasible; neither was the search for other children with similar characteristics in the neighborhood, because doing so would increase considerably the time to gather the in- 
formation and the costs. Therefore, this was considered as the baseline evaluation of the program, assuming that subsequent evaluations would be carried out and pre-post comparison evaluations would be feasible.

The study focused on the individual determinants of health services utilization; we did not address others, such as health systems or societal determinants. Also, the information was collected interviewing the mother or the main caretaker and reviewing the preventive care booklet of the child. Both sources have limitations (recall bias, mistakes and omissions in the registries of the booklet and the variability in the delivery of the booklet to the mother etc.) and this should be taken into account.

We can conclude that SMNG can be an important lever in promoting the access and uptake of preventive care, and in increasing the use of curative care among its affiliates. This can effectively boost the performance of Mexico's healthcare system. This is the first SMNG large-scale evaluation to be conducted and its results should be interpreted as the baseline data for subsequent evaluations. The fact that we did find more regular use of preventive care in the rural sample, and little difference between urban and rural samples regarding use of curative care, can be interpreted as a signal that the SMNG program is bridging the gaps in healthcare equity for Mexican children. Nevertheless, it is necessary to reinforce programs encouraging mothers to seek preventive care regularly, particularly focusing on those mothers with low literacy levels. An important target population would be pregnant women. Promoting regular attendance at antenatal care, including educational information about the importance of preventive care for their children, would be a key starting point in prompting the future use of well-child visits, which in turn will render positive results in the health status of vulnerable Mexican children.

Declaration of conflict of interests. The authors declare that they have no conflict of interests.

\section{References}

I. Anderson JG. Health services utilization: framework and review. Health Serv Res 1973;8:184-199.

2. Andersen R, Newman JF. Societal and Individual Determinants of Medical Care Utilization in the United States. Milbank Mem Fund Q Health Soc 1973;51:95-124.

3. Gutierrez G, Perez-Cuevas R, Levy S, Reyes H, Acosta B, FernandezCanton $S$, et al. Strengthening preventive care programs: a permanent challenge for healthcare systems; lessons from PREVENIMSS Mexico. BMC Public Health 2010;10:417.

4. Freed GL, Clark SJ, Pathman DE, Schectman R. Influences on the Receipt of Well-child Visits in the First Two Years of Life. Pediatrics 1999;103(4 Pt 2):864-869.
5. Elgewaily M, al-Sayyed J, Gadalla F. Factors influencing utilization of the preventive health services among children aged 6-60 months in Bahrain. Part I. J Egypt Public Health Assoc 1989;64:145-I54.

6. Hagelin E, Jackson K, Wikblad K. Utilization of Child Health Services during the first 18 months of life: aspects of health surveillance in Swedish preschool children based on information in health records. Acta Paediatr 1998;87:996-1002.

7. Kamau N, Esamai FO. Determinants of immunisation coverage among children in Mathare Valley, Nairobi. East Afr Med J 200I;78(I I):590-594.

8. Partha $D$, Bhattacharya $B N$. Determinants of child immunization in four less-developed states of north India. J Child Health Care 2002;6:34-50.

9. Bhuiya A, Bhuiya I, Chowdhury M. Factors affecting acceptance of immunization among children in rural Bangladesh. Health Policy Plan 1995;10:304-312.

10. Woods CR, Arcury TA, Powers JM, Preisser JS, Gesler WM. Determinants of Health Care Use by Children in Rural Western North Carolina: Results From the Mountain Accessibility Project Survey. Pediatrics 2003; I I2:el43-I52.

II. Thind A. Analysis of health services use for respiratory illness in Indonesian children: implications for policy. J Biosoc Sci 2005;37:129- 42.

12. Heck KE, Parker JD. Family structure, socioeconomic status, and access to health care for children. Health Serv Res 2002 Feb;37:173-186.

13. Taffa N, Chepngeno G. Determinants of health care seeking for childhood illnesses in Nairobi slums. Trop Med Int Health 2005; I 0:240-245. 14. Neumark Y, Palti H, Donchin M, Ellencweig AY. Utilization of pediatric health services in Jerusalem. J Community Health 1992;17:27I-282. 15. Valdespino JL, Olaiz G, López-Barajas MP, Mendoza L, Palma O, Velázquez O, et al. Encuesta Nacional de Salud 2000. Tomo I. Vivienda, población y utilización de servicios de salud. Cuernavaca, Morelos, México: Instituto Nacional de Salud Pública, 2003.

16. Olaiz-Fernández G, Rivera-Dommarco J, Shamah-Levy T, Rojas R, Villalpando-Hernández S, Hernández-Avila M, et al. Encuesta Nacional de Salud y Nutrición 2006. Cuernavaca, México: Instituto Nacional de Salud Pública, 2006.

17. Flores S, Ramos RI, Villa-Contreras S, Carranco T, Flores-Huerta S, Martínez-Salgado H. Utilización de los servicios de salud y cuidados en el hogar del niño enfermo. En: Levy-Algazi S, Muñoz-Hernández $\mathrm{O}$, Martínez-Salgado LH, Méndez-Blanco JP, Gutiérrez-Trujillo G, García Peña MC, et al. Prácticas de alimentación, estado de nutrición y cuidados a la salud en niños menores de 2 años en México. México: Instituto Mexicano del Seguro Social, 2004:227-25I.

18. Villalpando S, Shamah-Levy T, Ramírez-Silva C, Mejía Rodriguez FJR. Prevalence of anemia in children I to 12 years of age. Results from a nationwide survey in Mexico. Salud Publica Mex 2003;45:S490-S498. 19. Perdigón-Villaseñor G, Fernández-Cantón SB. La mortalidad neonatal y postneonatal en México, 1980-2005. Bol Med Hosp Infant Mex 2008; 65: $4|2-4| 4$.

20. OECD Reviews of Health Systems Mexico. Paris: Organization for Economic Cooperation and Development, 2005.

21 . Subsecretaría de Prevención y Promoción de la Salud. Programa de Acción Específico 2007-2012 Arranque Parejo en la Vida. México: Secretaría de Salud, 2007.

22. Orozco-Núñez E, González-Block MA, Kageyama-Escobar LM, Hernández-Prado B. Participación social en salud: la experiencia del programa de salud materna Arranque Parejo en la Vida. Salud Publica Mex 2009;51:104-II3.

23. Leroy JL, García-Guerra A, García R, Dominguez C, Rivera J, Neufeld LM. The Oportunidades Program Increases the Linear Growth of Children Enrolled at Young Ages in Urban Mexico. J Nutr 2008; I38:793-798. 24. Fernald LCH, Gertler P, Neufeld LM The Importance of Cash in Conditional Cash Transfer Programs for Child Health, Growth and Development: An Analysis of Mexico's Oportunidades. Lancet 2008; 37I: 828-837. 
25. Ezzati T, Khare M. Non-response adjustments in a national health survey. 1992. Proceedings of the Survey Research Methods Section of the American Statistical Association. Alexandria, Va: American Statistical Association 1993:339-344.

26. Bronfman M, Guiscafré H, Castro V, Castro R, Gutierrez G. Measuring inequality: a methodological approach, analysis of the social and economic characteristic of the sample studied. Arch Invest Med 1988;19:35I-360. 27. Mendoza-Sassi R, Beria JU. Health services utilization: a systematic review of related factors. Cad Saúde Pública 2001;17:819-832.
28. Archer KJ, Lemeshow S. Goodness-of-fit test for logistic regression model fitted using survey sample data. The Stata Journal 2006:97-105 29. Levy PS, Lemeshows. Sampling of Populations. 3rd ed. New York: Wiley, 1999.

30. Aday LA, Andersen R. A framework for the study of access to medical care. Health Serv Res 1974;9(3):208-220. 